\title{
AVA Biochem, Pioneer in Industrial Biobased Furan Chemistry
}

\author{
Stefan Krawielitzki*
}

\begin{abstract}
Swiss-based AVA Biochem AG is the global leader in the industrial production and sale of the biobased platform chemical 5-hydroxymethylfurfural (5-HMF), a renewable and non-toxic alternative to a range of petroleum-based materials. 5-HMF has a broad range of applications in the chemical, pharmaceutical and food industries. Since 2014 AVA Biochem has been producing high-purity 5-HMF for research purposes and specialty chemicals markets, as well as technical-grade 5-HMF for bulk chemistry applications. AVA Biochem's own R\&D department also develops the downstream chemistry of 5-HMF and thus opens the door to biobased furan chemistry on an industrial scale.
\end{abstract}

Keywords: Furan dicarboxylic acid (FDCA) - Hydrothermal processing $(\mathrm{HTC}) \cdot 5$-Hydroxymethylfurfural (5-HMF) · Polyethylenfuranoate (PEF) - UHMF/PHMF resins

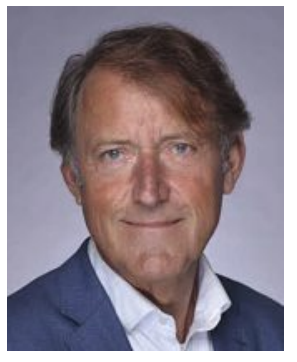

Dr. Stefan Krawielitzki studied chemistry at the Ludwig Maximilian University of Munich and obtained his doctorate in 1995 with research in the field of bioinorganic chemistry of sugars. He started his industrial career as Head of R\&D and Deputy Head of Analytics at the LGC laboratories, a worldwide active supplier of reference substances. As founder and CEO he led the company Synthon in Augsburg/Germany, which offered customer syntheses of rare or non available fine chemicals worldwide. Dr. Krawielitzki joined AVA Biochem in 2014 and as Head of R\&D is responsible for the development of the downstream chemistry of 5-HMF in its wide-ranging application possibilities and for business development.

\section{Business Case, Context, Motivation}

Since the beginning of industrialization, fossil raw materials have been regarded as the driving force behind human progress. In addition to covering the global energy demand for heating and electricity, a large part of modern chemical products, such as plastics and fuels, are based on fossil raw materials. This development undoubtedly paved the way for our current standard of living, but it also has its dark sides. The increasing exploitation of fossils, coupled with growing demand, is rapidly leading to a shortage of resources and further processing is causing massive environmental damage. This fact can be observed, among other things, in the advancing climate change, the spread of ozone holes or the accumulation of persistent pollutants in the biosphere and represents a major global challenge.

Growing awareness of the need for environmental protection measures and the enactment of environmentally compatible laws and regulations is just as much a challenge as the development of so-called 'green technologies'. 'Green chemistry' is regarded as a promising sub-area of these technologies. It pursues the development of sustainable chemical processes and products and thus sets itself ecological goals in addition to economic ones. The focus is on reducing the use of environmentally harmful chemicals, maximizing energy efficiency and increasing process safety. ${ }^{[1]}$

${ }^{\star}$ Correspondence: Dr. S. Krawielitzki, E-mail: s.krawielitzki@ava-biochem.com AVA Biochem BSL AG, Rothausstr. 61, CH-4132 Muttenz, Switzerland
AVA Biochem is one of a new breed of chemical companies at the forefront of sustainable, biobased chemistry for the $21 \mathrm{st}$ century. AVA's Hydrothermal Processing (HTP) technology is the only known continuous, fully up-scalable process for the production of 5-hydroxymethylfurfural (HMF), a key biobased platform chemical. AVA developed and patented this water-based efficient and robust process for the dehydration of fructose to HMF, which is now at an advanced production stage (TRL 9) and offers unrivaled economics to produce HMF (Fig. 1).

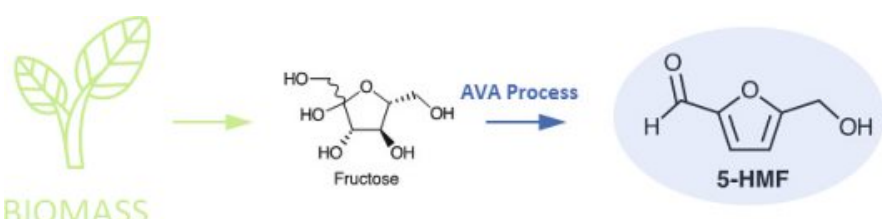

Fig. 1. Conversion of biomass to 5-HMF.

The world's first industrial plant dedicated to the production of HMF from biomass is operated by AVA in Muttenz, in which HMF can be produced from both conventional 1st-generation sugars, as well as from 2nd-generation sugars, provided these achieve a sufficient proportion of fructose.

As shown in more detail below, 5-HMF is a renewable alternative to petroleum-based materials and a popular platform molecule with huge potential as an important biobased commodity chemical ${ }^{[2,3]}$ for the synthesis of various commercially useful acids, aldehydes, alcohols, and amines, as well as the promising fuel 2,5-dimethylfuran (DMF) ${ }^{[4]}$ and renewable monomer furan dicarboxylic acid (FDCA). ${ }^{[5]} \mathrm{HMF}$ also has potential as a building block for the manufacture of commodity chemicals such as caprolactam, the precursor to Nylon $6,6^{[6]}$ following hydrogenation and hydrogenolysis to 1,6-hexanediol.

\section{Solution, Scientific Approach}

Since its first synthesis in 1895 from inulin and examination by Louis Maillard in 1912 in studies on non-enzymatic glucose reactions, the production of 5-HMF used to be a highly manual and protracted process, with limited possibilities for scale-up. AVA Biochem's HTC (hydrothermal carbonization) process allows for highly scalable and cost-efficient commercial-scale 5-HMF production. The modified HTC process was initially developed by 
AVA Biochem's parent company, AVA-CO2, in cooperation with the Karlsruhe Institute of Technology (KIT), to turn biomass waste into energy. The standard method of biomass transformation, thermal drying, is an energy-intensive process because the water present needs to be evaporated. AVA-CO2's HTC process was developed as a more sustainable, innovative method. AVA Biochem's approach is based on the carbonization of fructose. Compared to previous methods, the process allows for higher purities and better yields of 5-HMF production. Traditionally, when making 5-HMF, fructose was treated with acids and then underwent liquid-liquid extraction using organic solvents such as methyl isobutyl ketone. The HTC process hydrolyzes and then dehydrates biomass before it polymerizes it into larger biocoal molecules. During biomass carbonization, water molecules are removed in an exothermic process. Biocoal precursors, 5-HMF among them, are formed during this reaction. Whereas condensation or polymerization reactions in the conventional HTC process would turn biomass into biocoal, the modified HTC process allows for the extraction of 5-HMF before this stage, while still allowing the process to run continuously. As 5-HMF is not a very stable molecule and the HTC process follows many non-linear and irreversible reaction pathways, it was a challenge to design the process to achieve efficient extraction of the chemical. Due to the complexity of the HTC reaction, not all sugars react at the same time and not all sugars turn into 5-HMF or other biocoal precursors. The modifications to the HTC process included the recycling of non-reacted sugars to increase yields. The new process produces crystallized 5-HMF at commercial scale at purities of up to $99.9 \%$. Furthermore, it allows for the production of 5-HMF in aqueous solution, which opens the door to more applications.

5-HMF has two functional reactive groups - a primary hydroxyl group and a carbonyl group, also the furan ring itself is a reactive structure. Due to this fact, $\mathrm{HMF}$ can undergo a wide variety of chemical reactions and, already through selective oxidation or reduction, be a starting material for other platform chemicals. Examples are the oxidation products diformylfuran (DFF) and furan dicarboxylic acid (FDCA) (Scheme 1).

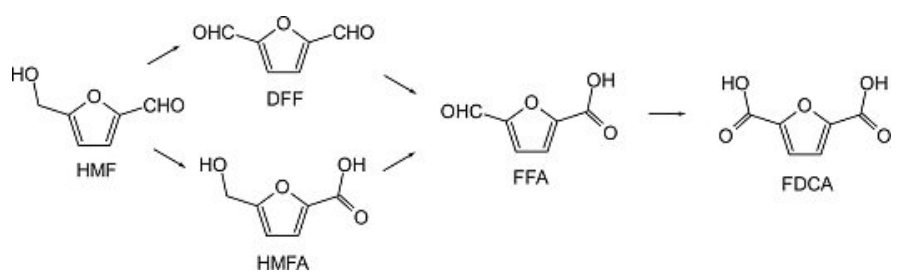

Scheme 1. Oxidation pathway from 5-HMF to FDCA.

In 2004, FDCA was identified by the U.S. Department of Energy (U.S. D.o.E.) as one of the twelve sugar-based building blocks which hold the greatest potential for the production of biobased chemicals and materials (Fig. 2). ${ }^{[7,8]}$ These twelve building blocks are commonly referred to as the bioplatform chemicals and have attracted increased amount of interest in recent years as replacement petrochemical products in a wide range of application areas.

One of the best known applications of FDCA is the replacement of fossil-based terephthalic acid in PET, whereby polyethylene furanoate PEF is obtained (Fig. 3). [9]

Replacing PET with renewable PEF could have a substantial impact on the packaging and bottling sectors, as $100 \%$ biobased PEF bottles could substitute for fossil-based PET bottles. Sustainability is not the only advantage PEF could bring to the industry. The PEF gas barrier is 10 times better than PET for oxygen and 5 times better for carbon dioxide, which could potentially allow for new application such as tea or beer packaging in PEF plastic bottles. Another advantage of PEF is its higher tensile strength, which would help reduce production costs.

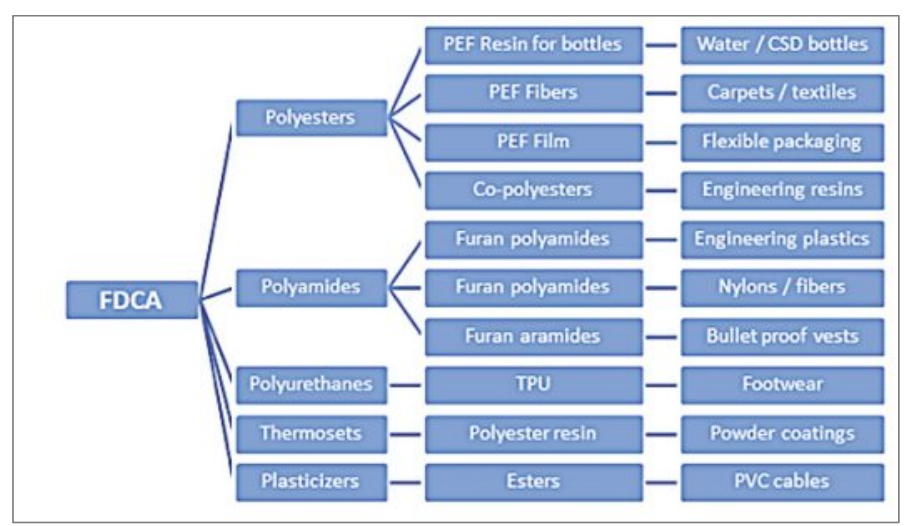

Fig. 2. Potential applications of FDCA.

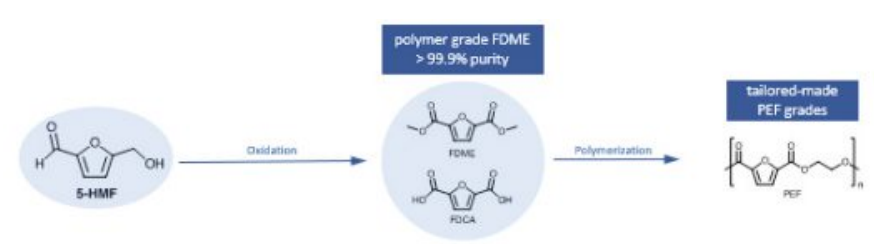

Fig. 3. Pathway to PEF.

Other key 5-HMF-derived chemicals are created when the platform chemical is reduced (Fig. 4). For example, 2,5-bis(hydroxymethyl)furan can be a widely used polymer and polyurethane foam building block. Other biobased polymers that could be made from 5-HMF include certain polyesters, polyamides, and resins.
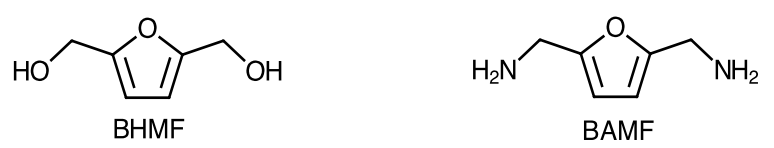

Fig. 4. Reduction products of 5-HMF.

The potential to replace formaldehyde or glyoxal through 5-HMF or its partial oxidation product DFF offers yet another important application. In view of formaldehyde's widespread use, toxicity, and volatility, exposure is a significant human health issue. In 2011, the US National Toxicology Program concluded that formaldehyde was "known to be a human carcinogen". [10] The replacement of formaldehyde through 5-HMF in applications such as textiles, pharmaceuticals, cosmetics and especially in UF, PF or MF resins, which are used on a huge scale in the woodworking industry for the production of particle boards or laminates is therefore of great significance for public health. AVA Biochem cooperates in this field with industrial companies on the development of non-toxic and non-carcinogenic urea-HMF and phenolicHMF resins.

Finally, 5-HMF could play an interesting role as an Active Pharmaceutical Ingredient (API). In 2006, 5-HMF was granted Orphan Drug Status by the US Food and Drug Administration (FDA) for the investigational prophylactic treatment of sickle cell disease. ${ }^{[11]}$ A recent study published in the journal Free Radical Research suggests that 5-HMF also prevents against oxidative injury via APE/Ref-1. ${ }^{[12]}$ Oxidative injury is involved in many disorders, including ischemic and neuro-degenerative diseases. Antioxidant drugs can be used to relieve the oxidative injury caused by these diseases, but there are few antioxidant drugs available for clinical use. The study found that 5-HMF protects against the oxidative damage induced by cerebral ischemia in rats by hydrogen peroxide in PC12 cells. 


\section{Product/Service and Outlook}

AVA Biochem has set itself the goal of further developing and diversifying the sustainable, biobased and fascinating chemistry of 5-HMF and its downstream products. Together with industrial partners and within the framework of funded research projects the company will be able to offer economic and ecological alternatives to petroleum-based chemistry on an industrial scale in the future. With AVA Biochem's scalable HTC process, 5-HMF is on the way to become an important bulk chemical. To reach price competitiveness with petro-based chemicals in the future, two aspects are critical. First, large quantities of feedstock for the production of fructose at competitive prices must be available close to the production site to minimize transport costs. Second, energy prices for the production process must be comparatively low, since the cost of energy is the other main influence on 5-HMF production. For these reasons, it is crucial for bulk production to consider site location and co-location benefits. If these criteria are fulfilled, large-scale 5-HMF production is within reach.

Recent innovations in biobased chemical technology such as the modified HTC process and industrial breakthroughs, including turning lignocellulosic biomass into sugars and the development of key platform molecule formations, are driving the expansion of the biobased products industry and the bioeconomy. These improvements will help grow the biobased chemicals market and help reduce society's dependence on fossil-based resources.

\section{AVA Biochem}

\section{AVA BIDCHEM}

AVA Biochem has developed, piloted and patented a fully water-based process for the conversion of industrial sugars into the $100 \%$ bio-based molecule 5-HMF. This platform chemical is ideally positioned to advantageously replace petroleum-sourced chemicals in various mass-market applications, due to its versatility, non-toxicity and bio-sourcing. Targeted applications include biopolymers (yarn, films, packaging), as well as resins and adhesives, where 5-HMF replaces highly toxic formaldehyde.

\section{Key Figures}

Founding Year 2014

Location(s)

Legal Form

Headquarter: Zug

Production: Muttenz

Founders

Scientific Advisors

\section{AG}

Peter Achermann

Jan Vyscocil

William Scott

Prof. Dr. Andrea Kruse

Chair holder

University of Hohenheim

Institute of Agricultural Engineering Department of Conversion Technologies of Biobased Resources

No. of employees 20

Total investment

\section{Key Inventions}

5- HMF

Hydrothermal Processing technology (HTP) has been developed, patented and piloted to convert C-6 sugars into the renewable platform chemical 5-hydroxymethylfurfural (5-HMF) in aqueous solution and crystals in various purities in industrial scale.

\section{Next Milestones}

2020-2022

Ava One:

Construction of a production plant with a capacity of 5-6 ktons/year

2020-2023

Global licensing out of the process

\section{Contact}

Contact Person

Dr. Stefan Krawielitzki, Head R\&D

Address

AVA Biochem BSL AG

Rothausstr. 61

4132 Muttenz

Email

contact@ava-biochem.com

Website

[1] P. T. Anastas, J. C. Warner, 'Green Chemistry', 1998, Frontiers, p. 640.

[2] R.-J. van Putten, J. C. van der Waal, E. de Jong, C. B. Rasrendra, H. J. Heeres, J. G. de Vries, Chem. Rev. 2013, 113, 1499.

[3] M. E. Zakrzewska , E. Bogel-Łukasik, R. Bogel-Łukasik, Chem. Rev. 2010, $111,397$.

[4] L. Hu, G. Zhao, W. W. Hao, X. Tang, Y. Sun, L. Lin, S. J. Liu, RSC Adv. 2012, 2, 11184.

[5] S. Dutta, S. De, B. Saha, ChemPlusChem 2012, 77, 259.

[6] T. Buntara, S. Noel, P. H. Phua, I. Melián-Cabrera, J. G. de Vries, H. J. Heeres, Angew. Chem. Int. Ed. 2011, 50, 7083.

[7] T. Werpy, J. Holladay, J. White, 'Top Value Added Chemicals from Biomass', PNNL-14808, Pac. Northw. Nat. Lab., Richland, WA, 2004

[8] J. J. Bozell, G. R. Petersen, Green Chem. 2010, 12, 539

[9] A. J. J. E. Eerhart, A. P. C. Faaij, M. K. Patel, Energy Environ. Sci. 2012, 5, 6407.

[10] Department of Health and Human Services, Public Health Services. National Toxicology Program: 12th Report on Carcinogens. June 10, 2011.

[11] Y. Waknine, 'New FDA orphan drugs: CellCept, ISIS 301012, 5-HMF', Medscape Medical News, June 09, 2006.

[12] J.-H. Zhang, Y. Di, L.-Y. Wu, Y.-L. He, T. Zhao, X. Huang, X.-F. Ding, K.-W. Wu, M. Fan, L.-L. Zhu, Free Radic. Res. 2015, 49, 86.

\section{License and Terms}

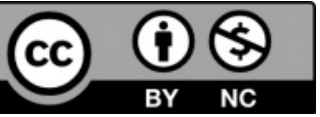

This is an Open Access article under the terms of the Creative Commons Attribution License CC BY_NC 4.0. The material may not be used for commercial purposes.

The license is subject to the CHIMIA terms and conditions: (http:// chimia.ch/component/sppagebuilder/?view=page \&id=12).

The definitive version of this article is the electronic one that can be found at https://doi.org:10.2533/chimia.2020.776 